\title{
Social Value Orientation Moderates the Effects of Intuition versus Reflection on Responses to Unfair Ultimatum Offers
}

\author{
Maik Bieleke ${ }^{1,2}$, Peter M. Gollwitzer ${ }^{1,3}$, Gabriele Oettingen ${ }^{3,4}$, Urs Fischbacher ${ }^{5,6}$ \\ ${ }^{1}$ Department of Psychology, University of Konstanz, 78457 Konstanz, Germany \\ ${ }^{2}$ Graduate School of Decision Sciences, University of Konstanz, 78457 Konstanz, Germany \\ ${ }^{3}$ Department of Psychology, New York University, New York, 10003, USA \\ ${ }^{4}$ Department of Psychology, University of Hamburg, 20146 Hamburg, Germany \\ ${ }^{5}$ Department of Economics, University of Konstanz, 78457 Konstanz, Germany \\ ${ }^{6}$ Thurgau Institute of Economics, 8280 Kreuzlingen, Switzerland
}

This is the accepted manuscript of an article published by Wiley in Journal of Behavioral Decision Making on 3 August 2016, available online: https://onlinelibrary.wiley.com/doi/abs/10.1002/bdm.1975. Please cite as follows:

Bieleke, M., Gollwitzer, P. M., Oettingen, G., \& Fischbacher, U. (2017). Social value orientation moderates the effects of intuition versus reflection on responses to unfair ultimatum offers. Journal of Behavioral Decision Making, 30(2), 569-581. https://doi.org/10.1002/bdm.1975

TOTAL WORD COUNT: 9’827 


\begin{abstract}
We investigated whether social value orientation (SVO) moderates the effects of intuitive versus reflective information processing on responses to unfair offers. We measured SVO one week prior to an ultimatum game experiment in which participants had to accept or reject a series of 10 ultimatum offers including very low (unfair) ones. Before making these decisions, participants mentally contrasted their individual goals with the obstacle of pondering at length or acting in a hasty way; then they made the plan to adopt an intuitive or a reflective mode of processing (intuitive and reflective condition, respectively), or made no such plans (control condition). Participants with rather high (prosocial) SVO scores were more likely to accept unfair offers in the reflective than the intuitive condition. This effect also evinced for a subset of selfish individuals; however, the majority with rather low (selfish) scores made similar decisions in both conditions. This pattern of results suggests that SVO moderates the effects of intuitive versus reflective modes of processing on responses to low ultimatum offers.
\end{abstract}

Keywords: ultimatum game; social value orientation (SVO); dual-process models; fairness; intuition versus reflection 


\section{Social Value Orientation Moderates the Effects of Intuition versus Reflection on Responses to Unfair Ultimatum Offers}

Many people dislike being treated in an unfair manner, and they are willing to spend resources to punish those who treat them unfairly (Camerer \& Thaler, 1995; Fehr, Fischbacher, \& Gächter, 2002; Fehr \& Gächter, 2000; Kahneman, Knetsch, \& Thaler, 1986; Rabin, 1993). This preference has often been analyzed with the ultimatum game (Güth, Schmittberger, \& Schwarze, 1982; for review see Güth \& Kocher, 2014). In this two-player game, the proposer receives a certain amount of money and offers the responder an allocation of this amount. If the responder accepts the offer, the amount is allocated as proposed; otherwise both players receive no money. Assuming common knowledge of rationality and selfishness, responders will accept any positive offer and proposers will make the smallest possible offer. In contradiction to this account, however, proposers commonly make offers in the range of 40 to $50 \%$ of the money, while many responders reject low offers below $20 \%$ (review by Camerer, 2003). The large offers made by proposers can at least partially be explained by strategic considerations (Bolton \& Zwick, 1995), but responder rejections of low offers are purely non-strategic and hence interpreted by most researchers as indicating a preference for being treated fairly (Fehr \& Gächter, 2000).

In recent years, it has been debated whether and how the way people process information in the ultimatum game affects the decision to accept or reject unfair offers. This question lies at the heart of dual-process models which distinguish between two modes of information processing, an intuitive and a reflective one, that govern decision making (J. S. B. T. Evans, 2008; Haidt, 2001; Kahneman, 2011; Strack \& Deutsch, 2004; Weber \& Johnson, 2009). The intuitive mode is assumed to concert processes that are fast, efficient and affect-based, permitting swift and effortless responses. The reflective mode, in contrast, is thought to rely on time and cognitive resources, affording prudent and considered decisions. But how does adopting one or the other mode of processing affect responses to unfair offers as observed in the ultimatum game? Are people more likely to accept unfair offers when they reflect upon their decisions, or when they rely on their intuition? A growing body of literature addresses this question and consistently reports that adopting different modes of processing is consequential for the decision to accept or reject unfair offers. However, the nature of these consequences is still an open question.

\section{Effects of Adopting Intuitive versus Reflective Modes of Processing on Responses to Unfair} Ultimatum Offers 
On the one hand, there is considerable research suggesting that low acceptance rates for unfair offers result from negative affect (e.g., anger and disgust) or scarce cognitive resources, both characteristic of an intuitive mode of processing. For instance, acceptance decisions have been observed to correlate negatively with self-reported feelings of anger (Pillutla \& Murnighan, 1996) as well as with activity in brain areas that are associated with intuitive processing (e.g., Sanfey, Rilling, Aronson, Nystrom, \& Cohen, 2003; Tabibnia, Satpute, \& Lieberman, 2008). Speaking to the causal role of negative emotions for these effects, providing people with emotion-regulation strategies increases acceptance rates (Kirk, Gollwitzer, \& Carnevale, 2011; van 't Wout, Chang, \& Sanfey, 2010), whereas depleting the resources required for self-regulation reduces them (Halali, BerebyMeyer, \& Meiran, 2013, Exp. 1). Additional supportive evidence comes from studies in which the cognitive resources available to participants were strained, tantamount to promoting intuitive modes of processing which, in contrast to reflective modes, do not require such resources. For instance, forcing people to make their decisions in short time resulted in lower acceptance rates of unfair offers compared to imposing rather loose time constraints (Sutter, Kocher, \& Strauß, 2003), whereas people obliged to pause before making their decision exhibit higher acceptance rates compared to situations without such a delay (Grimm \& Mengel, 2011; Neo, Yu, Weber, \& Gonzalez, 2013). Taken together, these studies yield profound support for the assumption that adopting a reflective mode of processing increases the likelihood of accepting unfair offers, as compared to an intuitive mode.

Interestingly, there are also studies with opposite results, demonstrating that unfair offers are more likely to be accepted in an intuitive than a reflective mode of processing. For instance, Knoch, Gianotti, Baumgartner, and Fehr (2010) have shown that baseline activity in prefrontal cortex areas is negatively correlated with acceptance rates for unfair offers. As lower baseline activity in these areas is commonly associated with less reflective processing (Miller \& Cohen, 2001), this finding suggests that people intuitively act in a selfish manner and accept unfair offers. If the relation is causal, derogation of the prefrontal cortex should lead to an increase in acceptance rates. This hypothesis was supported by applying repeated transcranial magnetic stimulation (rTMS) to disrupt the prefrontal cortex, causing responders to accept more unfair offers (Knoch et al., 2008; Knoch, Pascual-Leone, Meyer, Treyer, \& Fehr, 2006; van 't Wout, Kahn, Sanfey, \& Aleman, 2005). Although physiological studies using rTMS are commonly considered a valuable complement in research on social decision making processes (e.g., Rilling \& Sanfey, 2011), these results should be taken with a grain of salt. rTMS provides researchers with strong experimental control but in turn 
lacks ecological validity, compared to other processing manipulations (e.g., cognitive load).

Consequently, it is not clear whether impeded prefrontal cortex activity can be directly equated with intuitive processing, or rather reflects a mere lack of reflective processing. It is thus important to note that the findings from rTMS studies have been replicated using more common manipulations; once by depleting self-regulatory resources (Achtziger, Alós-Ferrer, \& Wagner, 2016) and once again by instructing participants to make quick decisions rather than thoughtful ones (Hochman, Ayal, \& Ariely, 2015). Both manipulations promoted an intuitive over a reflective mode of processing in a way that resembles everyday contexts (i.e., being exhausted and intending to use one processing mode over the other) and rendered participants more likely to accept unfair offers.

At the bottom line, all of these studies share the observation that adopting an intuitive versus a reflective mode of processing has consequences for the decision to accept unfair offers in the ultimatum game. Research linking ultimatum rejections to intuitive processing has so far generated more support in terms of the quantity and diversity of experimental evidence (e.g., ego depletion, emotion regulation, and time pressure) than research linking them to reflective processing, especially because the latter is still primarily based on evidence from rTMS studies. Yet, none of the hypotheses can be clearly rejected at this point, leaving the nature of intuitive versus reflective processing consequences on responder decisions unclear. How can we move on and address such inconsistent findings? A promising approach is to identify moderators of intuitive versus reflective processing effects on responses to unfair offers.

\section{The Moderating Role of Social Value Orientation (SVO)}

In the present research we turned to the concept of social value orientation (SVO; Messick \& McClintock, 1968; Murphy \& Ackermann, 2014; van Lange, 1999), a simple measure of prosociality that is likely related to the decision to accept or reject unfair offers in an ultimatum game (see below). SVO captures preferences for allocating resources between oneself and another person, and two main types of preferences are commonly distinguished (Au \& Kwong, 2004; Bogaert, Boone, \& Declerck, 2008). Individuals with cooperative (prosocial) preferences are willing to sacrifice their own resources to establish equal allocations and/or to maximize the mutual benefit. Individuals with individualistic (selfish) preferences, in contrast, solely focus on their personal benefits, trying to maximize their own resources and largely ignoring consequences for others. Besides these two main types, there are also small groups of people with either competitive preferences (trying to obtain more resources than the other person, even if this comes at an own cost) 
or altruistic preferences (trying to maximize the resources of the other, even when this requires to forfeit own benefits).

The preferences reflected by SVO have been associated with patterns of social interactions from early childhood to old age (e.g., van Lange, Otten, De Bruin, \& Joireman, 1997), and they are ubiquitous in everyday life. For instance, differences in SVO govern pro-environmental behavior (Gärling, Fujii, Gärling, \& Jakobsson, 2003), political ideologies (van Lange, Bekkers, Chirumbolo, \& Leone, 2012), the willingness to sacrifice in close relationships (van Lange, Agnew, Harinck, \& Steemers, 1997), the readiness to help others (van Lange, Schippers, \& Balliet, 2011), and the generosity of charitable donations (Bekkers, 2007). SVO is rather stable over time (Bogaert et al., 2008; Murphy, Ackermann, \& Handgraaf, 2011), and has consistently been shown to predict social decisions in experiments. In particular, prosocial individuals are more likely to cooperate in social dilemmas than selfish individuals (reviews by Balliet, Parks, \& Joireman, 2009; Bogaert et al., 2008; van Lange, Joireman, Parks, \& Van Dijk, 2013).

In sum, SVO has been widely used to study social decision making both in the lab and in everyday interactions, and it captures meaningful individual differences in these decisions. SVO thus lends itself well as a simple measure of prosociality that is probably associated with the response to unfair ultimatum offers. How it is related to the decision to accept or reject unfair offers is, however, not a priori clear. Prosocial responders could be unconditionally kind, forgiving unfair proposers and accepting their low offers; alternatively, they might be motivated to enforce a social norm to act fairly and thus reject unfair offers. Selfish responders might accept unfair offers because doing so maximizes their profit; it is, however, also conceivable that they grudge unfair proposers their larger share of money, and this envy could cause them to reject low offers. Such heterogeneity among prosocial and selfish individuals in ultimatum games is corroborated by the finding that prosociality and responses to unfair offers are not correlated (Peysakhovich, Novak, \& Rand, 2014; Yamagishi et al., 2012). That is, neither prosocial nor selfish individuals seem to systematically accept or reject unfair offers.

However, to our knowledge there are two studied which actually find a systematic relation between prosociality and responses to unfair ultimatum offers. One study (Haruno, Kimura, \& Frith, 2014) observed that people with prosocial preferences are less likely to accept unfair offers than those with selfish preferences under varying degrees of cognitive load. This result is consistent with the view that prosocial, but not selfish people, intuitively dislike unequal allocations (e.g., Cornelissen, Dewitte, \& Warlop, 2011; Haruno \& Frith, 2010; Haruno et al., 2014; Kuss et al., 2015) 
and are thus less likely to accept low offers which, by construction, would result in rather unequal allocations if accepted. This interpretation is, however, hard to reconcile with another study (Karagonlar \& Kuhlman, 2013) that did not impose load and found selfish people to be less likely to accept an unfair offer compared to prosocials. The authors attribute their observation to differences in emotion regulation: whereas selfish people might fail to regulate their anger and spite when facing unfair offers and thus reject, prosocials accept the unfair offer because they succeed in regulating such negative emotional responses.

In sum, there is scarce and conflicting evidence on how differences in SVO are reflected in responses to unfair offers, ranging from studies that find no correlation to studies observing that more prosocial individuals are either more or less likely to accept unfair offers. This makes it difficult to derive a specific hypothesis about how SVO moderates the effects of intuitive versus reflective processing on ultimatum game responses. However, by systematically analyzing this association in both an intuitive and a reflective mode of processing, the present research can potentially contribute to the current debate.

\section{Methods}

\section{Participants}

We recruited a total of 192 student participants using the online recruitment system ORSEE (Greiner, 2015). Of these participants, 32 were assigned to the role of a proposer and thus did not contribute to the data set. 160 participants were assigned to the role of a responder; we did not obtain data from 6 participants due to hardware failure. Ten responders did not want to adopt the suggested mode of information processing (see below; 7 in the reflective and 3 in the intuitive condition) but their decisions are nevertheless included in the analyses to prevent self-selection bias and permit causal inferences (i.e., we used an intention-to-treat approach; Hollis \& Campbell, 1999). This results in a final sample size of 154 participants (69 female; age: $M=23.22, S D=2.81$ ). The experiment was programmed and conducted with the software z-Tree (Fischbacher, 2007).

\section{Materials and Procedure}

Screening session. In the screening session we measured participants' social value orientation (SVO) with the Slider Measure (Murphy et al., 2011), a well-validated tool for assessing SVO (Murphy \& Ackermann, 2014). The Slider Measure comprises 6 items with 9 different allocation options lying on a specific line in the plane of one's own payoff and the other's payoff (e.g., $[50,100],[54,98], \ldots,[81,87],[85,85])$. By choosing one of these options, participants allocate the specified points between themselves and a randomly selected other participant. For instance, 
participants choosing a $[85,85]$ option assigned 85 points both to themselves and to the other participant. Based on these six items, we calculated a continuous SVO score. Participants could in principle be categorized according to their SVO score as exhibiting competitive, individualistic (selfish), cooperative (prosocial), or altruistic social preferences. However, using the continuous score is strongly recommended over relying on the nominal categories (Fiedler, Glöckner, Nicklisch, \& Dickert, 2013; Murphy \& Ackermann, 2014), and we therefore used the score in all the statistical analyses. Higher SVO scores correspond to more prosocial preferences; lower scores on the other hand represent more selfish preferences. We incentivized the SVO Slider measure but postponed information about SVO outcomes and the resulting payment until the end of the experimental session to avoid carry-over effects (e.g., compensating for a low payment).

We additionally used the screening session to assess participants' appraisals of intuitive and reflective processing modes, which have been shown to affect responder decisions in ultimatum games (Mussel, Göritz, \& Hewig, 2013). This allowed us to check that participants did not differ with regard to these appraisals between the processing conditions established later in the experiment. We used a German version (Keller, Bohner, \& Erb, 2000) of the Rational Experiential Inventory (REI; Epstein, Pacini, Denes-Raj, \& Heier, 1996). The German REI is a 29-item self-report measure with two subscales assessing how people judge their own ability to process information intuitively (faith-in-intuition; e.g., "I trust my initial feelings about people," $\alpha=0.86$ ) and their willingness to engage in reflective over intuitive processing (need-for-cognition; e.g., "I don't like to have to do a lot of thinking (reversed), $" \alpha=0.81$ ). Participants indicated how much they agreed with each statement on 7-point Likert scales ranging from 1 (do not agree) to 7 (totally agree), and we averaged their answers into intuitive and reflective preference scores.

Experimental session. The experimental session took place one week after the screening session to assure that assessing SVO and the preferred mode of processing would not affect decisions in the ultimatum game. Participants read the ultimatum game instructions and then worked on a practice trial showing the relevant decision screens for proposers and responders. Afterwards, they were told about their role in the games (i.e., either proposer or responder).

Strategy choice. Before they started working on the ultimatum games, proposers and responders in the control condition learned that they would engage in a 15 min task that was neither incentivized nor related to the ultimatum game (i.e., they searched letters in a nonsense text). These participants were not provided with a rationale for this task; they neither received any information on what other participants did during the 15 min time period. Responders in the intuitive and the 
reflective condition, in contrast, received a brief description of either the intuitive or reflective mode of processing strategy, and we requested them to choose between the respective strategy and the neutral task. They were given this choice to ensure that they would not feel patronized by the instructions. Participants did choose between either intuitive versus neutral or reflective versus neutral; they never had the choice between the two strategies. Those who opted for a mode of processing strategy $(90.2 \%$ of the participants who were given the choice; $94.2 \%$ in the intuitive and $86.0 \%$ in the reflective condition; Fisher's exact test, $p=.196$ ) then learned about the strategy, whereas the remaining participants received the neutral task. All participants worked for a fixed 15 min time period on the documents they received.

Intuitive versus reflective strategy. Participants started with specifying their most important wishes for the upcoming decisions and imagined the best outcome of realizing their wishes. In the intuitive condition, participants were then instructed to consider pondering at length about the decisions as a potential obstacle for attaining their goal, and made a plan specifying how to overcome this obstacle: "If I start pondering at length, then I will tell myself: Listen to your guts!" Analogously, participants in the reflective condition thought about acting in a hasty way as an obstacle and made the plan: "If I start acting in a hasty way, then I will tell myself: Use your brain!" This method of planning out how to respond when encountering an obstacle for goal achievement is known in psychology as "mental contrasting with implementation intentions" (Gollwitzer, 1999; Oettingen, Pak, \& Schnetter, 2001; Oettingen, Wittchen, \& Gollwitzer, 2013; Oettingen, 2012); it enables people to recognize the specified obstacle immediately as it emerges and to automatically initiate the pre-specified response (e.g., Achtziger, Bayer, \& Gollwitzer, 2012; Achtziger, Fehr, Oettingen, \& Gollwitzer, 2009; Kappes, Singmann, \& Oettingen, 2012; Kappes, Wendt, Reinelt, \& Oettingen, 2013). In the present research, we used this strategy to prepare participants to strategically switch to an intuitive versus reflective mode of processing as soon as they found themselves pondering at length or acting in a hasty way, respectively.

Ultimatum game. After the $15 \mathrm{~min}$ had elapsed, participants proceeded with playing 10 ultimatum game rounds. In each round, we presented them two allocations of 20 points: a fixed benchmark allocation yielding 9 points for the responder and 11 points for the proposer (i.e., a [9,11] allocation), and an alternative allocation favoring the proposer more strongly (e.g., a [3,17] allocation). One of these allocations was then offered to them and they could accept or reject this offer. In case of a rejection, both players received 0 points, otherwise the proposed allocation was 
implemented. Both the responder and the proposer received feedback about the outcome at the end of each round.

In each experimental session we had twenty responders and four proposers. In two rounds, the offer was made by one of the proposers (following a perfect stranger protocol) who could choose between the $[9,11]$ benchmark allocation and a randomly generated alternative allocation that would have given them a higher payoff (e.g., a [3,17] allocation). In the remaining rounds the offer was selected from a pre-determined sequence of allocations ([9,11], [6,14], [2,18], [9,11], [3,17], [9,11], $[1,19]$, and $[4,16]$ ) (see Sutter et al., 2003, for a similar procedure). This was done to ensure that each responder would experience a sufficiently high number of low offers, as these were of primary interest in the present research. At the same time, our design enabled us to include proposals by human proposers - a feature that is integral for eliciting rejections of low offers (van 't Wout, Kahn, Sanfey, \& Aleman, 2006). Note that participants were not deceived in our study; we informed them about the use of computer-generated offers, however without detailing the exact share of these offers. Moreover, responders never knew whether the offer they currently faced was made by a proposer or by the computer, preventing them from responding differently to these two types of offers.

Questionnaires. Prior studies in the domain of ultimatum games have shown that unfair offers elicit feelings of anger and spite (e.g., Pillutla \& Murnighan, 1996), so we checked whether our implementation of the ultimatum game produced such negative affect as well. Immediately after the ultimatum game decisions, we therefore assessed participants' experienced affect with the 20-item Positive and Negative Affect Schedule (PANAS; Watson, Clark, \& Tellegen, 1988). In this selfreport measure, participants indicate the extent to which they experience 10 positive (e.g., excited, enthusiastic, proud; $\alpha=0.85$ ) and 10 negative (e.g., upset, guilty, ashamed; $\alpha=0.87$ ) emotions on a 5 -point Likert scale $(1=$ very slightly or not at all, 5 = extremely $)$. We averaged the answers into scores for positive and negative affect, respectively, to assess overall experienced affect. Importantly, the PANAS also includes some items that are specifically related to feelings of anger and spite (e.g., feeling upset) that we could use to check the success of our fairness manipulation in the ultimatum game.

We also wanted to check that participants in the intuitive and the reflective condition understood and adopted their respective mode of processing plans. To probe their understanding, we presented three pairs of statements (i.e., six items altogether, $\alpha=.77$ ) to assess the degree to which these participants in the intuitive and reflective condition felt that their plan required them to respond 
slowly $(\alpha=.75)$, to think carefully $(\alpha=.72)$, and to make the most beneficial decisions $(\alpha=.34)$.

Because in all three pairs the statements were essentially reversed (e.g., "I felt instructed to make my decisions slowly" versus "I felt instructed to make my decisions quickly"), we reverse-scored one of the items and then averaged across the two scores. This resulted in three composite scores indicating the degree to which participants understood their respective processing manipulations. We also measured how committed participants were to adopt the assigned mode of processing with a 4-item commitment scale (e.g., "I was strongly committed to the plan," $\alpha=0.75$ ) that has been validated for research purposes (Klein, Wesson, Hollenbeck, Wright, \& DeShon, 2001). We averaged these items into a single commitment score.

\section{Analysis}

The data was analyzed with the statistical software R (R Core Team, 2014) and visualized with the package ggplot2 (Wickham, 2009). When regression results are reported, statistical inference is based on robust standard error estimates clustered on the responder level (154 clusters). We coded offers of three points or less (i.e., $<20 \%$ of the available 20 points) as unfair, because offers of this size are commonly rejected by many responders (Camerer, 2003). Higher offers were coded as fair. The main dependent variable in the ultimatum game is whether an offer was accepted or rejected; however, we also measured response times as an additional manipulation check for our mode of processing manipulation. An overview of the descriptive statistics of all variables we assessed in our experiment along with their inter-correlations is given in Table A1.

\section{Screening Session}

The overall distribution of SVO scores $(M=18.86, S D=13.61)$ is depicted in Figure 1. Eighty-seven participants were classified as selfish (intuitive: 31 , control: 28 , reflective: 28 ), 65 as prosocial (intuitive: 20, control: 23, reflective: 22), 2 as competitive (intuitive: 1, control: 1, reflective: 0 ), and none as altruistic. The SVO types were evenly distributed across the experimental conditions (Fisher's exact test, $p=.900$ ). The analysis of the Rational Experiential Inventory revealed that participants scored higher on the faith-in-intuition $(M=4.93, S D=0.85)$ than on the need-for-cognition subscale $(M=4.24, \mathrm{SD}=0.73), t(153)=6.91, p<.001$. Importantly, we found no differences between the processing conditions, $F_{\mathrm{s}}<1$.

\section{Manipulation Checks}


Understanding and adopting the processing plans. Our data suggest that participants understood and adopted their respective modes of processing. Across all six items, we found a significant difference between the intuitive and the reflective condition, $t(90)=10.14, p<.001$. Specifically, an analysis of the three composite scores revealed that reflective participants felt more required to decide slowly $(M=5.28, S D=1.26$ versus $M=2.22, S D=1.03), t(90)=12.81, p<.001)$ and to think carefully $(M=5.45, S D=1.34$ versus $M=2.99, S D=1.44), t(90)=8.46, p<.001$ than intuitive participants. They also felt slightly more prompted to make the most beneficial decisions $(M=5.20, S D=1.24$ versus $M=4.77, S D=1.35)$ but this difference was not significant, $t(90)=$ $1.59, p=.114$, even when we conducted the analysis separately for the two corresponding items due to the low $\alpha$ of the composite score $(p s>.156)$. Finally, participants in the intuitive $(M=4.04, S D=$ $1.52)$ and the reflective $(M=4.39, S D=1.52)$ condition were similarly committed to act on their plans, $t(90)=1.14, p=.258$, indicating that they tried to adopt the respective mode of processing.

Response times. Rather than planning to make fast versus slow decisions, participants made plans to rely on their gut feelings versus their reflective thought, and yet they associated the former with making faster decisions than the latter (see above). If participants actually made faster responses, we expect differences in response times to show up primarily for responses to unfair offers, as these pose a conflict between acceptance and rejection decisions and thus might give rise to the obstacles of finding oneself pondering at length or acting hastily.

--- Insert Figure 2 about here ---

We found some support for this idea, as we observed faster responses to unfair offers among intuitive $(M=6.99, S D=2.75)$ compared to reflective participants $(M=8.38, S D=4.45)$, illustrated in Figure 2. To test this observation, we regressed response times on the effects of condition and fairness, as well as their interaction effect. Although Levene's test indicated no significant heteroscedasticity among the processing conditions, $F(2,151)=2.196, p=.115$, we conducted the statistical analyses with a robust regression approach that corrects for potential heteroscedasticity. The contrast of intuitive versus reflective participants approached significance when the offer was unfair, $\beta=1.42, t=1.93, p=0.054$, but was clearly insignificant when the offer was fair, $\beta=0.54, t$ $=1.02, p=0.308$, resulting in a marginally significant interaction effect of fairness and condition, $\beta$ $=-0.88, t=1.69, p=0.091$. This pattern of results is consistent with the structure of the processing 
plans. Considered jointly with the questionnaire analysis, the response time analysis suggests that participants understood, adopted, and acted upon their assigned processing plans.

Affect. Overall, participants reported more positive $(M=2.42, S D=0.74)$ than negative affect $(M=1.80, S D=0.71), t(153)=8.29, p<.001$. However, this finding is hardly surprising given that the PANAS scales cover a broad range of affective states, many of them probably irrelevant in the context of ultimatum games. We found no differences between the mode of processing conditions with regard to these feelings, $F<1$.

\section{Responder Decisions}

About 2/3 of all offers were accepted in the experiment. As illustrated in Figure 3, low offers of $\leq 3$ points were much less likely accepted than the remaining offers, $\beta=3.35, z=22.55, p<.001$, corroborating the interpretation of these low offers as unfair. We analyzed responder decisions (coded 1 if the offer was accepted, 0 otherwise) using several logistic regressions with robust standard errors clustered on the responder level (154 clusters); that is, responses from the same participant were considered as correlated. To test our hypothesis that SVO moderates the effects of adopting an intuitive versus a reflective mode of processing on responses to unfair ultimatum offers, we regressed responder decisions on the effects of condition and SVO, as well as their interaction effect. ${ }^{1}$ When evaluating regressions with an interaction term, note that we mean-centered the continuous SVO score to render lower-order effects conditional on the observed average SVO score of $M=18.86$, rather than an SVO score of 0 (following a recommendation by Aiken \& West, 1990). This makes the conditional effects of SVO and condition displayed in the regression table more representative for the overall sample.

--- Insert Figure 3 about here ---

Considering fair and unfair offers jointly (see Table 1, Models A1 to A4), participants in the reflective condition were more likely to accept offers than those in the intuitive condition, $\beta=0.33, z$ $=2.31, p=.021$, with the control condition falling in between. This result indicates that the mode of processing affected responder decisions in a meaningful way. The effect of belonging to the

\footnotetext{
${ }^{1}$ Recent evidence suggests gender differences in participants' responses to ultimatum offers (e.g., Dulebohn et al., 2016). In our study, however, we found no gender differences in the propensity to reject offers in general or unfair offers in particular across conditions, $p \mathrm{~s}>.52$; moreover, females and males were equally distributed across the intuitive and reflective conditions, $\chi^{2}(1)=0.04, p=.849$. As a consequence, the effect of gender was non-significant in all of our models ( $p$ s between .21 and .94), and adding it to the regression models did not alter our main findings.
} 
reflective rather than the intuitive condition was not moderated by SVO, $\beta=0.02, z=1.53, p=.125$. However, we expected SVO to moderate processing mode effects only with regard to unfair offers. We therefore regressed responder decisions on the effects of processing condition, SVO and their interaction effect separately for fair (Table 1, Models F1 to F4) and unfair (Table 1, Models U1 to U4) offers.

Not surprisingly, we observed only little variation in responses to fair offers. Participants in the reflective condition were marginally more likely to accept fair offers than those in the intuitive condition, $\beta=0.47, z=1.88, p=.060$. Neither the effect of SVO, $\beta=-0.005, z=0.59, p=.554$, nor the interaction effect of condition and SVO, $\beta=0.01, z=0.68, p=.498$, reached conventional levels of significance, however.

\section{--- Insert Table 1 about here ---}

In contrast, responses to unfair offers varied as a function of both condition and SVO (see Figure 4). Participants in the reflective condition were significantly more likely to accept unfair offers than those in the intuitive condition, $\beta=0.82, z=1.97, p=.048$. Moreover, we observed a significant effect of SVO, $\beta=-0.03, z=2.38, p=.017$, such that higher (i.e., more prosocial) SVO scores were associated with a lower likelihood of accepting unfair offers. Finally, adding the interaction effect of SVO and processing condition to the analysis (Model U4) significantly improved model fit, $\chi^{2}(2)=6.86, p=.032$, and the interaction effect itself was significant as well, SVO, $\beta=0.06, z=2.00, p=.045$. Specifically, higher SVO scores were associated with a lower probability of accepting unfair offers in the intuitive condition, whereas differences in SVO did not play out in the reflective condition.

--- Insert Figures 4 and 5 about here ---

To further scrutinize this result, we probed the difference between the intuitive and the reflective condition with regard to unfair offers across the entire range of SVO scores observed in our study. Specifically, we plotted the log odds ratio of accepting an unfair offer when belonging to the reflective rather than to the intuitive condition as a function of SVO score in Figure 5, along with the $95 \%$ confidence interval. For instance, the log odds ratio was estimated to be 1.15 for participants with an average SVO score of 18.86 (see Table 1), tantamount to an approximately three 
times larger odds of accepting an unfair offer when belonging to the reflective rather than the intuitive condition (note that $\exp (1.15)=3.16$ ).

Figure 5 presents the estimated log odds ratio across all SVO scores, permitting a full examination of the effects of adopting an intuitive versus reflective mode of processing. The difference between the intuitive and the reflective condition turns out to be significant for SVO scores larger than approximately 13.8 in our study. In the SVO Slider Measure people with scores between -12.04 and 22.45 are classified as selfish, while people with scores between 22.45 and 57.15 are classified as prosocial. Accordingly, the range of significant SVO scores covers all individuals with a prosocial SVO score, and also a subset of selfish individuals. To be specific, out of 87 participants who were classified as selfish in our experiment, 24 exhibited SVO scores that belong to the region of significance (27.6\%). Taken together, the analysis of responder decisions supports our hypothesis that SVO moderates the effects of adopting an intuitive versus reflective mode of processing on responses to unfair offers.

\section{Additional Analyses}

In the analyses reported so far we coded offers of less than $20 \%$ of the available points (i.e., 1 , 2 , or 3 points) as unfair. We had chosen this cutoff because offers of this size are commonly rejected by many responders (Camerer, 2003). However, our experimental design also comprised a $[4,16]$ allocation and one might wonder whether this allocation should be considered unfair as well. Across participants and conditions the rejection rates were $86.1 \%, 82.3 \%$, and $73.5 \%$ for the $[1,19],[2,18]$, and $[3,17]$ offers, respectively, while the rejection rate of the $[4,16]$ offer was substantially lower at $43.9 \%$. As a consequence, analyzing responder decisions with the $[4,16]$ offer coded as unfair revealed reduced effect sizes of SVO, processing mode, and their interaction effect, while the pattern of results was retained. This finding corroborates our initial choice to code offers of 3 points or less as unfair.

Further evidence comes from a continuous investigation of the interaction effect of SVO and processing mode. In this analysis, we computed the odds of rejecting each of the nine possible offers $([1,19],[2,18], \ldots,[9,11])$ across participants and conditions as a continuous indicator of fairness. Next, we divided each of these odds by the odds of rejecting the $[9,11]$ benchmark offer. This resulted in a continuous odds ratio index measuring how unfair an offer was in comparison to the benchmark offer. We observed a three-way interaction effect of this odds ratio index, the intuitive vs. reflective processing condition, and SVO, $\beta=0.0002, z=2.13, p=.033$. In line with our cutoff 
choice for unfair offers, follow-up tests indicated that the interaction effect of intuitive vs. reflective processing condition and SVO was significant only for [1,19], [2,18], and [3,17] offers.

\section{Discussion}

We examined whether social value orientation (SVO; Messick \& McClintock, 1968; Murphy \& Ackermann, 2014; van Lange, 1999) moderates the effects of adopting an intuitive versus reflective mode of processing on responses to unfair ultimatum offers. We assessed SVO one week prior to an ultimatum game experiment in which participants faced a series of ultimatum offers they had to accept or reject. We found that planning to adopt an intuitive versus a reflective mode of processing prior to making these decisions primarily affected prosocial individuals; they were less likely to accept unfair offers when they adopted an intuitive rather than a reflective mode of processing. While this effect also evinced for a subset of selfish individuals, the majority of them was not affected, making similar decisions in both the intuitive and the reflective condition. This pattern of results supports our hypothesis that SVO moderates the effects of intuitive versus reflective modes of processing on responses to unfair offers.

\section{Implications for Research on Information Processing in Social Decision Making}

Previous work has primarily focused on the main effects of adopting an intuitive versus a reflective mode of processing on responses to unfair offers, examining how people decide on average. Although this research has revealed consequences for responses to unfair offers, so far the results did not converge into consistent conclusions regarding the nature of these consequences (e.g., Achtziger et al., 2016; Grimm \& Mengel, 2011; Hochman et al., 2015; Knoch et al., 2008; Sutter et al., 2003). We accordingly propose to explore moderators of the effects of intuitive versus reflective modes of processing, and our results suggest SVO as such a moderator. The present research is thus a first step in developing a better understanding of the consequences of intuitive versus reflective modes of processing for responses to unfair offers. Our approach might, however, also be relevant for other domains of social decision making than responding to unfairness in which the effects of intuitive versus reflective modes of processing are unclear (e.g., Rand \& Kraft-Todd, 2014; Zaki \& Mitchell, 2013). For instance, generosity in dictator games, a variant of the ultimatum game in which the responder cannot reject the offer, also yields contradictory findings with regard to effects of adopting an intuitive versus a reflective mode of processing (Achtziger, Alós-Ferrer, \& Wagner, 2015; Schulz, Fischbacher, Thöni, \& Utikal, 2014). Consistent with our findings, SVO has been found to moderate the effects of intuitive versus reflective processing modes on generosity in these games (Cornelissen et al., 2011). 
It is also important to note that it is currently debated which experimental evidence can be used to draw inferences about the effects of processing modes on social decisions. In particular, it has been argued that response times might depend more strongly on decision conflict than on different processing modes (Evans, Dillon, \& Rand, 2015; Krajbich, Bartling, Hare, \& Fehr, 2015). According to this argument, fast responses do not necessarily reflect a more intuitive mode of processing than slow responses, rendering inferences based on measured response times difficult. However, we relied on an experimentally induced mode of processing that led to changes in responses to unfair offers, along with differences in response times (see Lotz, 2015, and Rand, Greene, \& Nowak, 2012, for similar approaches in the domain of cooperative behavior). Thus, our findings do not reflect decision conflict, permitting us to draw valid conclusions about processing effects on social decision making.

Our findings are also in line with the social heuristics hypothesis (Bear \& Rand, 2016; Rand \& Kraft-Todd, 2014; Rand et al., 2014; Rand, Greene, \& Nowak, 2012), which asserts that intuitive decisions rely on social preferences, whereas reflective decisions foster profit maximization regardless of these preferences. However, prior research on the hypothesis has not taken into account potential differences in SVO as a possible measure of social preferences. Assuming that SVO is associated with everyday social interaction across the lifespan (van Lange et al., 1997) however the social heuristics hypothesis predicts the pattern of results that we found in our study: differences between prosocial and selfish people evinced in the intuitive condition but not in the reflective condition. Although we did not set up our study to explicitly test the social heuristics hypothesis, our results therefore suggest that future studies may rely on it to derive specific predictions about how intuitive versus reflective modes of processing affect social interactions.

\section{Implications for Research on Social Value Orientation (SVO)}

The present research contributes to the current discussion of how SVO affects responder decisions in the ultimatum game. Our results are consistent with one study observing that people with prosocial preferences are less likely to accept unfair offers than those with selfish preferences under varying degrees of cognitive load (Haruno et al., 2014); our data similarly suggest that prosocials are more likely than selfish people to accept unfair offers when adopting an intuitive rather than a reflective mode of processing. However, another study (Karagonlar \& Kuhlman, 2013) found that selfish people experience strong feelings of anger when facing an unfair offer and fail to effectively down-regulate this emotional response, resulting in a lower likelihood of accepting the offer compared to prosocials. This finding is hard to reconcile with our data, given that we never 
observed that selfish people were less likely than prosocials to accept unfair offers, neither when adopting an intuitive nor when adopting a reflective mode of processing.

A possible explanation pertains to procedural differences between the studies; the study by Haruno, Kimura, and Frith (2014) and our own study relied on several ultimatum game rounds comprising a range of both unfair and fair offers. Karagonlar and Kuhlman (2013), in contrast, used a one-shot ultimatum game with a single unfair offer ( 2 out of 10 points). The failure to regulate anger observed among selfish individuals might be particularly prevalent when only a single unfair offer is evaluated, compared to when a range of fair and unfair offers is evaluated over the course of multiple rounds. To test this idea, we re-analyzed decisions focusing on the round in which responders first encountered an unfair offer. As in our main analysis, we found that higher SVO scores predicted a lower probability of accepting unfair offers in the intuitive condition, whereas SVO scores did not predict responder decisions in the reflective condition. This pattern of results was still not compatible with the findings of Karagonlar and Kuhlman. On a cautionary note, however, even the first round in our experiment does not fully resemble a one-shot situation as it is embedded in a series of games. Accordingly, our speculations about why differences between studies occurred remain tentative and we feel that future research should address this issue directly.

Finally, it is interesting that adopting an intuitive versus a reflective mode of processing did not only affect prosocial individuals but also some individuals with rather high SVO scores among those classified as selfish. This result is consistent with research stressing the importance of gradual differences in SVO that can be masked when researchers rely on nominal classifications only (Fiedler et al., 2013; Murphy \& Ackermann, 2014). The present research provides additional support for this reasoning.

\section{Societal Implications}

Beyond its conceptual and methodological implications our research also has broader implications on the societal level. Many situations in daily life involve ultimatum bargaining (Fehr \& Gächter, 2000), ranging from rather mundane situations like grocery shopping or the sharing behavior among children (Murnighan \& Saxon, 1998) to more momentous ones such as marriage decisions of couples (Güth, Ivanova-Strenzel, \& Tjotta, 2004) or professional trading behavior in competitive markets (Bolton \& Ockenfels, 2014). The ultimatum game is a simple model of these complex behaviors and yet it captures the underlying preference for being treated fairly. This makes the ultimatum game a widely used paradigm to study anthropological (e.g., evolution, Fehr \& Fischbacher, 2003; cultural variations, Henrich et al., 2001), sociological (e.g., gender differences, 
Solnick, 2001; social distance effects, Charness \& Gneezy, 2008), and individual (e.g., relations to personality, Brandstätter \& Königstein, 2001; effects of mental disorders, Koenigs \& Tranel, 2007) aspects of the fairness preferences involved in ultimatum bargaining. Given the ecologic importance of ultimatum bargaining and its comprehensive investigation with the ultimatum game, a sound understanding of processes and decision outcomes is of utmost importance. Our findings substantially advance this understanding by demonstrating how individual differences in prosociality (measured by SVO) determine the effects of intuitive versus reflective processing modes on the revealed preference for being treated fairly. 


\section{Acknowledgments}

The authors thank three anonymous referees for several helpful and constructive comments which helped improving an earlier version of this paper. Financial support by the German Research Foundation (DFG) through the Research Unit "Psychoeconomics" (FOR 1882) is gratefully acknowledged. 


\section{References}

Achziger, A., Alós-Ferrer, C., \& Wagner, A. K. (2016). The impact of self-control depletion on social preferences in the ultimatum game. Journal of Economic Psychology, 53, 1-33. doi: 10.1016/j.joep.2015.12.005

Achtziger, A., Alós-Ferrer, C., \& Wagner, A. K. (2015). Money, depletion, and prosociality in the dictator game. Journal of Neuroscience, Psychology, and Economics, 8, 1-14. doi: 10.1037/npe0000031

Achtziger, A., Bayer, U. C., \& Gollwitzer, P. M. (2012). Committing to implementation intentions: Attention and memory effects for selected situational cues. Motivation and Emotion, 36, 287300. doi: 10.1007/s11031-011-9261-6

Achtziger, A., Fehr, T., Oettingen, G., \& Gollwitzer, P. M. (2009). Strategies of intention formation are reflected in continuous MEG activity. Social Neuroscience, 4, 11-27. doi: $10.1080 / 17470910801925350$

Aiken, L. S., \& West, S. G. (1990). Multiple regression: Testing and interpreting interactions. Thousand Oaks: Sage.

Au, W. T., \& Kwong, J. Y. Y. (2004). Measurement and effects of social-value orientation in social dilemmas. In R. Suleiman, D. V Budescu, I. Fischer, \& D. M. Messick (Eds.), Contemporary psychological research on social dilemmas (pp. 71-98). New York, NY: Cambridge University Press.

Balliet, D., Parks, C., \& Joireman, J. (2009). Social value orientation and cooperation in social dilemmas: A meta-analysis. Group Processes \& Intergroup Relations, 12, 533-547. doi: $10.1177 / 1368430209105040$

Bekkers, R. (2007). Measuring altruistic behavior in surveys: The all-or-nothing dictator game. Survey Research Methods, 1, 139-144.

Bogaert, S., Boone, C., \& Declerck, C. (2008). Social value orientation and cooperation in social dilemmas: A review and conceptual model. The British Journal of Social Psychology, 47, 453480. doi: $10.1348 / 014466607 X 244970$

Bolton, G. E., \& Zwick, R. (1995). Anonymity versus punishment in ultimatum bargaining. Games and Economic Behavior, 10, 95-121. doi: 10.1006/game.1995.1026

Brandstätter, H., \& Königstein, M. (2001). Personality influences on ultimatum bargaining decisions. European Journal of Personality, 15, S53-S70. doi: 10.1002/per.424

Camerer, C. F. (2003). Behavioral game theory: Experiments in strategic interaction. New York: Princeton University Press.

Camerer, C. F., \& Thaler, R. H. (1995). Anomalies: Ultimatums, dictators and manners. Journal of Economic Perspectives, 9, 209-219. doi: 10.1257/jep.9.2.209

Charness, G., \& Gneezy, U. (2008). What's in a name? Anonymity and social distance in dictator and ultimatum games. Journal of Economic Behavior and Organization, 68, 29-35. doi: 10.1016/j.jebo.2008.03.001

Cornelissen, G., Dewitte, S., \& Warlop, L. (2011). Are social value orientations expressed automatically? Decision making in the dictator game. Personality and Social Psychology Bulletin, 37, 1080-1090. doi: 10.1177/0146167211405996

Dulebohn, J., Davison, R., Lee, S., Conlon, D., McNamara, G., \& Sarinopoulos, I. (2016). Gender differences in justice evaluations: Evidence from fMRI. Journal of Applied Psychology, 101, 151-170. doi: 10.1037/ap10000048

Epstein, S., Pacini, R., Denes-Raj, V., \& Heier, H. (1996). Individual differences in intuitiveexperiential and analytical-rational thinking styles. Journal of Personality and Social 
Psychology, 71, 390-405. doi: 10.1037/0022-3514.71.2.390

Evans, A. M., Dillon, K. D., \& Rand, D. G. (2015). Fast but not intuitive, slow but not reflective: Decision conflict drives reaction times in social dilemmas. Journal of Experimental Psychology: General, 144, 951-966. doi: 10.1037/xge0000107

Evans, J. S. B. T. (2008). Dual-processing accounts of reasoning, judgment, and social cognition. Annual Review of Psychology, 59, 255-278. doi: 10.1146/annurev.psych.59.103006.093629

Fehr, E., \& Fischbacher, U. (2003). The nature of human altruism. Nature, 425, 785-791. doi: 10.1038/nature02043

Fehr, E., Fischbacher, U., \& Gächter, S. (2002). Strong reciprocity, human cooperation, and the enforcement of social norms. Human Nature, 13, 1-25. doi: 10.1007/s12110-002-1012-7

Fehr, E., \& Gächter, S. (2000). Fairness and retaliation: The economics of reciprocity. Journal of Economic Perspectives, 14, 159-182. doi: 10.1257/jep.14.3.159

Fiedler, S., Glöckner, A., Nicklisch, A., \& Dickert, S. (2013). Social value orientation and information search in social dilemmas: An eye-tracking analysis. Organizational Behavior and Human Decision Processes, 120, 272-284. doi: 10.1016/j.obhdp.2012.07.002

Fischbacher, U. (2007). Z-Tree: Zurich toolbox for ready-made economic experiments. Experimental Economics, 10, 171-178. doi: 10.1007/s10683-006-9159-4

Gärling, T., Fujii, S., Gärling, A., \& Jakobsson, C. (2003). Moderating effects of social value orientation on determinants of proenvironmental behavior intention. Journal of Environmental Psychology, 23, 1-9. doi: 10.1016/S0272-4944(02)00081-6

Gollwitzer, P. M. (1999). Implementation intentions: Strong effects of simple plans. American Psychologist, 54, 493-503. doi: 10.1037/0003-066X.54.7.493

Greiner, B. (2015). Subject pool recruitment procedures: Organizing experiments with ORSEE. Journal of the Economic Science Association, 1, 114-125. doi: 10.1007/s40881-015-0004-4

Grimm, V., \& Mengel, F. (2011). Let me sleep on it: Delay reduces rejection rates in ultimatum games. Economics Letters, 111, 113-115. doi: 10.1016/j.econlet.2011.01.025

Güth, W., \& Kocher, M. G. (2014). More than thirty years of ultimatum bargaining experiments: Motives, variations, and a survey of the recent literature. Journal of Economic Behavior and Organization, 108, 396-409. doi: 10.1016/j.jebo.2014.06.006

Güth, W., Schmittberger, R., \& Schwarze, B. (1982). An experimental analysis of ultimatum bargaining. Journal of Economic Behavior \& Organization, 3, 367-388. doi: 10.1016/01672681(82)90011-7

Haidt, J. (2001). The emotional dog and its rational tail: A social intuist approach to moral judgment. Psychological Review, 108, 814-834. doi: 10.1037//0033-295X. 108.4.814

Halali, E., Bereby-Meyer, Y., \& Meiran, N. (2013). Between self-interest and reciprocity: The social bright side of self-control failure. Journal of Experimental Psychology: General, 143, 745-54. doi: $10.1037 / \mathrm{a} 0033824$

Haruno, M., \& Frith, C. D. (2010). Activity in the amygdala elicited by unfair divisions predicts social value orientation. Nature Neuroscience, 13, 160-161. doi: 10.1038/nn.2468

Haruno, M., Kimura, M., \& Frith, C. D. (2014). Activity in the nucleus accumbens and amygdala underlies individual differences in prosocial and individualistic economic choices. Journal of Cognitive Neuroscience, 26, 1861-1870. doi: 10.1162/jocn

Henrich, B. J., Boyd, R., Bowles, S., Camerer, C., Fehr, E., Gintis, H., \& McElreath, R. (2001). In search of Homo Economicus: Behavioral experiments in 15 small-scale societies. American Economic Review, 91, 73-78.

Hochman, G., Ayal, S., \& Ariely, D. (2015). Fairness requires deliberation: The primacy of 
economic over social considerations. Frontiers in Psychology, 6. doi: $10.3389 /$ fpsyg.2015.00747

Hollis, S., \& Campbell, F. (1999). What is meant by intention to treat analysis? Survey of published randomised controlled trials. British Medical Journal, 319, 670-674. doi: $10.1136 / \mathrm{bmj} .319 .7211 .670$

Kahneman, D. (2011). Thinking, fast and slow. New York, NY: Farrar, Straus and Giroux.

Kahneman, D., Knetsch, J. L., \& Thaler, R. H. (1986). Fairness and the assumptions of economics. The Journal of Business, 59, S285-S300. doi: 10.1086/296367

Kappes, A., Singmann, H., \& Oettingen, G. (2012). Mental contrasting instigates goal pursuit by linking obstacles of reality with instrumental behavior. Journal of Experimental Social Psychology, 48, 811-818. doi: 10.1016/j.jesp.2012.02.002

Kappes, A., Wendt, M., Reinelt, T., \& Oettingen, G. (2013). Mental contrasting changes the meaning of reality. Journal of Experimental Social Psychology, 49, 797-810. doi: 10.1016/j.jesp.2013.03.010

Karagonlar, G., \& Kuhlman, D. M. (2013). The role of social value orientation in response to an unfair offer in the ultimatum game. Organizational Behavior and Human Decision Processes, 120, 228-239. doi: 10.1016/j.obhdp.2012.07.006

Keller, J., Bohner, G., \& Erb, H.-P. (2000). Intuitive and heuristic judgment - different processes? Presentation of a German version of the rational-experiential inventory and of new self-report scales of heuristic use. Zeitschrift für Sozialpsychologie, 31, 87-101. doi: 10.1024//00443514.31.2.87

Kirk, D., Gollwitzer, P. M., \& Carnevale, P. J. (2011). Self-regulation in ultimatum bargaining: Goals and plans help accepting unfair but profitable offers. Social Cognition, 29, 528-546. doi: $10.1521 /$ soco.2011.29.5.528

Klein, H. J., Wesson, M. J., Hollenbeck, J. R., Wright, P. M., \& DeShon, R. P. (2001). The assessment of goal commitment: A measurement model meta-analysis. Organizational Behavior and Human Decision Processes, 85, 32-55. doi: 10.1006/obhd.2000.2931

Knoch, D., Gianotti, L. R. R., Baumgartner, T., \& Fehr, E. (2010). A neural marker of costly punishment behavior. Psychological Science, 21, 337-342. doi: 10.1177/0956797609360750

Knoch, D., Nitsche, M. A., Fischbacher, U., Eisenegger, C., Pascual-Leone, A., \& Fehr, E. (2008). Studying the neurobiology of social interaction with transcranial direct current stimulation The example of punishing unfairness. Cerebral Cortex, 18, 1987-1990. doi: 10.1093/cercor/bhm237

Knoch, D., Pascual-Leone, A., Meyer, K., Treyer, V., \& Fehr, E. (2006). Diminishing reciprocal fairness by disrupting the right prefrontal cortex. Science, 314, 829-832. doi: $10.1126 /$ science. 1129156

Koenigs, M., \& Tranel, D. (2007). Irrational economic decision-making after ventromedial prefrontal damage: Evidence from the Ultimatum Game. Journal of Neuroscience, 27, 951956. doi: 10.1523/JNEUROSCI.4606-06.2007

Krajbich, I., Bartling, B., Hare, T., \& Fehr, E. (2015). Rethinking fast and slow based on a critique of reaction-time reverse inference. Nature Communications, 6. doi: 10.1038/ncomms 8455

Kuss, K., Falk, A., Trautner, P., Montag, C., Weber, B., \& Fliessbach, K. (2015). Neuronal correlates of social decision making are influenced by social value orientation - An fMRI study. Frontiers in Behavioral Neuroscience, 9. doi: 10.3389/fnbeh.2015.00040

Messick, D. M., \& McClintock, C. G. (1968). Motivational bases of choice in experimental games. Journal of Experimental Social Psychology, 4, 1-25. doi: 10.1016/0022-1031(68)90046-2 
Miller, E. K., \& Cohen, J. D. (2001). An integrative theory of prefrontal cortex function. Annual Review of Neuroscience, 24, 167-202. doi: 10.1146/annurev.neuro.24.1.167

Murphy, R. O., \& Ackermann, K. A. (2014). Social value orientation: Theoretical and measurement issues in the study of social preferences. Personality and Social Psychology Review, 18, 13-41. doi: $10.1177 / 1088868313501745$

Murphy, R. O., Ackermann, K. A., \& Handgraaf, M. J. J. (2011). Measuring social value orientation. Judgment \& Decision Making, 6, 771-781. doi: 10.2139/ssrn.1804189

Mussel, P., Göritz, A. S., \& Hewig, J. (2013). Which choice is the rational one? An investigation of need for cognition in the ultimatum game. Journal of Research in Personality, 47, 588-591. doi: 10.1016/j.jrp.2013.05.007

Neo, W. S., Yu, M., Weber, R. A., \& Gonzalez, C. (2013). The effects of time delay in reciprocity games. Journal of Economic Psychology, 34, 20-35. doi: 10.1016/j.joep.2012.11.001

Oettingen, G. (2012). Future thought and behaviour change. European Review of Social Psychology, 23, 1-63. doi: 10.1080/10463283.2011.643698

Oettingen, G., Pak, H., \& Schnetter, K. (2001). Self-regulation of goal setting: Turning free fantasies about the future into binding goals. Journal of Personality and Social Psychology, 80, 736-753. doi: 10.1037/0022-3514.80.5.736

Oettingen, G., Wittchen, M., \& Gollwitzer, P. M. (2013). Regulating goal pursuit through mental contrasting with implementation intentions. In A. E. Locke \& G. Latham (Eds.), New developments in goal setting and task performance (pp. 523-548). New York, NY: Routledge.

Peysakhovich, A., Nowak, M. A., \& Rand, D. G. (2014). Humans display a "cooperative phenotype" that is domain general and temporally stable. Nature Communications, 5. doi: 10.1038/ncomms5939

Pillutla, M. M., \& Murnighan, J. K. (1996). Unfairness, anger, and spite: Emotional rejections of ultimatum offers. Organizational Behavior and Human Decision Processes, 68, 208-224. doi: 10.1006/obhd.1996.0100

R Core Team. (2014). R: A language and environment for statistical computing. Vienna: R Foundation for Statistical Computing. Retrieved from http://www.r-project.org/

Rabin, M. (1993). Incorporating fairness into game theory and economics. American Economic Review, 83, 1281-1302.

Rand, D. G., Greene, J. D., \& Nowak, M. A. (2012). Spontaneous giving and calculated greed. Nature, 489, 427-430. doi: 10.1038/nature11467

Rand, D. G., \& Kraft-Todd, G. T. (2014). Reflection does not undermine self-interested prosociality. Frontiers in Behavioral Neuroscience, 8. doi: 10.3389/fnbeh.2014.00300

Rand, D. G., Peysakhovich, A., Kraft-Todd, G. T., Newman, G. E., Wurzbacher, O., Nowak, M. A., \& Greene, J. D. (2014). Social heuristics shape intuitive cooperation. Nature Communications, 5, 3677. doi: $10.1038 /$ ncomms4677

Rilling, J. K., \& Sanfey, A. G. (2011). The neuroscience of social decision making. Annual Review of Psychology, 62, 23-48. doi: 10.1146/annurev.psych.121208.131647

Sanfey, A. G., Rilling, J. K., Aronson, J. A., Nystrom, L. E., \& Cohen, J. D. (2003). The neural basis of economic decision-making in the ultimatum game. Science, 300, 1755-1758. doi: 10.1126/science. 1082976

Schulz, J. F., Fischbacher, U., Thöni, C., \& Utikal, V. (2014). Affect and fairness: Dictator games under cognitive load. Journal of Economic Psychology, 41, 77-87. doi: 10.1016/j.joep.2012.08.007

Solnick, S. J. (2001). Gender differences in the ultimatum game. Economic Inquiry, 39, 189-200. 
doi: $10.1093 / \mathrm{ei} / 39.2 .189$

Strack, F., \& Deutsch, R. (2004). Reflective and impulsive determinants of social behavior. Personality and Social Psychology Review, 8, 220-247. doi: 10.1207/s15327957pspr0803_1

Sutter, M., Kocher, M., \& Strauß, S. (2003). Bargaining under time pressure in an experimental ultimatum game. Economics Letters, 81, 341-347. doi: 10.1016/S0165-1765(03)00215-5

Tabibnia, G., Satpute, A. B., \& Lieberman, M. D. (2008). The sunny side of fairness: Preference for fairness activates reward circuitry (and disregarding unfairness activates self-control circuitry). Psychological Science, 19, 339-347. doi: 10.1111/j.1467-9280.2008.02091.x

van 't Wout, M., Chang, L. J., \& Sanfey, A. G. (2010). The influence of emotion regulation on social interactive decision-making. Emotion (Washington, D.C.), 10(6), 815-821. doi: $10.1037 / \mathrm{a} 0020069$

van 't Wout, M., Kahn, R. S., Sanfey, A. G., \& Aleman, A. (2005). Repetitive transcranial magnetic stimulation over the right dorsolateral prefrontal cortex affects strategic decision-making. Neuroreport, 16, 1849-1852. doi: 10.1097/01.wnr.0000183907.08149.14

van 't Wout, M., Kahn, R. S., Sanfey, A. G., \& Aleman, A. (2006). Affective state and decisionmaking in the Ultimatum Game. Experimental Brain Research, 169, 564-568. doi: 10.1007/s00221-006-0346-5

van Lange, P. A. M. (1999). The pursuit of joint outcomes and equality in outcomes: An integrative model of social value orientation. Journal of Personality and Social Psychology, 77, 337-349. doi: 10.1037/0022-3514.77.2.337

van Lange, P. A. M., Agnew, C. R., Harinck, F., \& Steemers, G. E. M. (1997). From game theory to real life: How social value orientation affects willingness to sacrifice in ongoing close relationships. Journal of Personality and Social Psychology, 73, 1330-1344. doi: 10.1037/0022-3514.73.6.1330

van Lange, P. A. M., Bekkers, R., Chirumbolo, A., \& Leone, L. (2012). Are conservatives less likely to be prosocial than liberals? From games to ideology, political preferences, and voting. European Journal of Personality, 26, 461-473. doi: 10.1002/per.845

van Lange, P. A. M., Joireman, J., Parks, C. D., \& Van Dijk, E. (2013). The psychology of social dilemmas: A review. Organizational Behavior and Human Decision Processes, 120, 125-141. doi: 10.1016/j.obhdp.2012.11.003

van Lange, P. A. M., Otten, W., De Bruin, E. M., \& Joireman, J. A. (1997). Development of prosocial, individualistic, and competitive orientations: Theory and preliminary evidence. Journal of Personality and Social Psychology, 73, 733-746. doi: 10.1037/0022-3514.73.4.733

van Lange, P. A. M., Schippers, M., \& Balliet, D. (2011). Who volunteers in psychology experiments? An empirical review of prosocial motivation in volunteering. Personality and Individual Differences, 51, 279-284. doi: 10.1016/j.paid.2010.05.038

Watson, D., Clark, L. A., \& Tellegen, A. (1988). Development and validation of brief measures of positive and negative affect: The PANAS scales. Journal of Personality and Social Psychology, 54, 1063-1070. doi: 10.1037/0022-3514.54.6.1063

Weber, E. U., \& Johnson, E. J. (2009). Mindful judgment and decision making. Annual Review of Psychology, 60, 53-85. doi: 10.1146/annurev.psych.60.110707.163633

Wickham, H. (2009). ggplot2: Elegant graphics for data analysis. New York: Springer.

Yamagishi, T., Horita, Y., Mifune, N., Hashimoto, H., Li, Y., Shinada, M., ... Simunovic, D. (2012). Rejection of unfair offers in the ultimatum game is no evidence of strong reciprocity.

Proceedings of the National Academy of Sciences, 109, 20364-8. doi: 10.1073/pnas.1212126109 
Zaki, J., \& Mitchell, J. P. (2013). Intuitive prosociality. Current Directions in Psychological Science, 22, 466-470. doi: 10.1177/0963721413492764 
Tables

Table 1

Logistic regression models for explaining responses in the ultimatum game $(1=$ accept, $0=$ reject $)$. Baseline is an SVO score of 18.86 in the intuitive condition

\begin{tabular}{|c|c|c|c|c|c|c|c|c|c|c|c|c|}
\hline \multirow[b]{2}{*}{ Model } & \multicolumn{4}{|c|}{ All Offers } & \multicolumn{4}{|c|}{ Unfair Offers } & \multicolumn{4}{|c|}{ Fair Offers } \\
\hline & A1 & $\mathrm{A} 2$ & A3 & A4 & U1 & $\mathrm{U} 2$ & U3 & $\mathrm{U} 4$ & $\mathrm{~F} 1$ & $\mathrm{~F} 2$ & F3 & $\mathrm{F} 4$ \\
\hline Intercept & $\begin{array}{l}0.54^{* * *} \\
(0.09)\end{array}$ & $\begin{array}{l}0.68^{* * *} \\
(0.06)\end{array}$ & $\begin{array}{l}0.53^{* * *} \\
(0.09)\end{array}$ & $\begin{array}{l}0.53^{* * *} \\
(0.08)\end{array}$ & $\begin{array}{l}-1.90^{* * *} \\
(0.32)\end{array}$ & $\begin{array}{l}-1.47^{* * *} \\
(0.17)\end{array}$ & $\begin{array}{l}-2.01^{* * *} \\
(0.30)\end{array}$ & $\begin{array}{l}-2.23^{* * *} \\
(0.30)\end{array}$ & $\begin{array}{l}1.78^{* * *} \\
(0.16)\end{array}$ & $\begin{array}{l}1.93^{* * *} \\
(0.10)\end{array}$ & $\begin{array}{l}1.77^{* * *} \\
(0.16)\end{array}$ & $\begin{array}{l}1.78^{* * *} \\
(0.15)\end{array}$ \\
\hline $\begin{array}{l}\text { Condition = } \\
\text { Control }\end{array}$ & $\begin{array}{r}0.10 \\
(0.14)\end{array}$ & & $\begin{array}{r}0.12 \\
(0.14)\end{array}$ & $\begin{array}{r}0.12 \\
(0.14)\end{array}$ & $\begin{array}{r}0.53 \\
(0.42)\end{array}$ & & $\begin{array}{r}0.61 \\
(0.42)\end{array}$ & $\begin{array}{c}0.82^{*} \\
(0.41)\end{array}$ & $\begin{array}{r}0.04 \\
(0.23)\end{array}$ & & $\begin{array}{r}0.05 \\
(0.23)\end{array}$ & $\begin{array}{r}0.03 \\
(0.23)\end{array}$ \\
\hline $\begin{array}{l}\text { Condition = } \\
\text { Reflective }\end{array}$ & $\begin{array}{c}0.33^{*} \\
(0.14)\end{array}$ & & $\begin{array}{c}0.34^{*} \\
(0.14)\end{array}$ & $\begin{array}{c}0.34^{* *} \\
(0.14)\end{array}$ & $\begin{array}{c}0.82^{*} \\
(0.41)\end{array}$ & & $\begin{array}{c}0.88^{*} \\
(0.40)\end{array}$ & $\begin{array}{l}1.15^{* *} \\
(0.40)\end{array}$ & $\begin{array}{c}0.47^{\dagger} \\
(0.25)\end{array}$ & & $\begin{array}{c}0.48^{\dagger} \\
(0.25)\end{array}$ & $\begin{array}{c}0.47^{\dagger} \\
(0.25)\end{array}$ \\
\hline $\mathrm{SVO}^{\mathrm{a}}$ & & $\begin{array}{l}-0.01^{\dagger} \\
(0.00)\end{array}$ & $\begin{array}{l}-0.01^{\dagger} \\
(0.00)\end{array}$ & $\begin{array}{l}-0.02^{* *} \\
(0.01)\end{array}$ & & $\begin{array}{l}-0.03^{*} \\
(0.01)\end{array}$ & $\begin{array}{l}-0.03^{*} \\
(0.01)\end{array}$ & $\begin{array}{l}-0.06^{* *} \\
(0.02)\end{array}$ & & $\begin{array}{l}-0.00 \\
(0.01)\end{array}$ & $\begin{array}{l}-0.00 \\
(0.01)\end{array}$ & $\begin{array}{l}-0.02 \\
(0.01)\end{array}$ \\
\hline $\begin{array}{l}\text { Control } \times \\
\text { SVO }^{\mathrm{a}}\end{array}$ & & & & $\begin{array}{r}0.01 \\
(0.01)\end{array}$ & & & & $\begin{array}{r}0.02 \\
(0.03)\end{array}$ & & & & $\begin{array}{r}0.02 \\
(0.02)\end{array}$ \\
\hline $\begin{array}{l}\text { Reflective } \times \\
\text { SVO }^{\text {a }}\end{array}$ & & & & $\begin{array}{r}0.02 \\
(0.01)\end{array}$ & & & & $\begin{array}{c}0.06^{*} \\
(0.03)\end{array}$ & & & & $\begin{array}{r}0.01 \\
(0.02)\end{array}$ \\
\hline Num. obs. & 1540 & 1540 & 1540 & 1540 & 478 & 478 & 478 & 478 & 1062 & 1062 & 1062 & 1062 \\
\hline Pseudo $\mathrm{R}^{2}$ & 0.01 & 0.00 & 0.01 & 0.01 & 0.03 & 0.04 & 0.07 & 0.09 & 0.01 & 0.00 & 0.00 & 0.01 \\
\hline L.R. & 6.42 & 4.27 & 10.92 & 13.86 & 7.88 & 11.19 & 20.27 & 27.13 & 4.90 & 0.43 & 5.38 & 7.71 \\
\hline
\end{tabular}

Note. Numbers in parentheses are robust standard errors clustered on the responder level (154 clusters).

${ }^{a}$ Mean-centered variable.

${ }^{\dagger} p<.1 .^{*} p<.05 .{ }^{* *} p<.01 .^{* * *} p<.001$. 
Figures

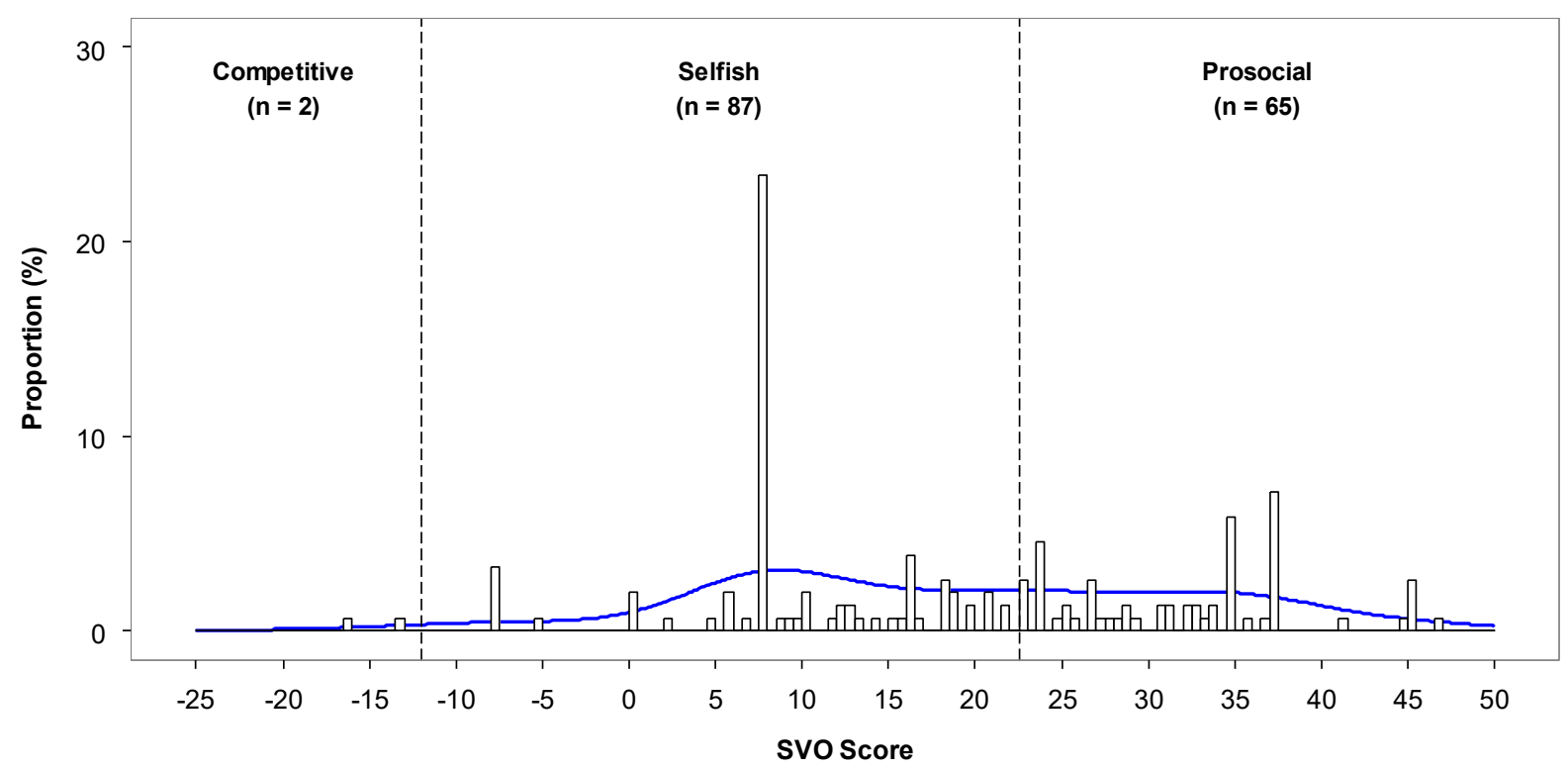

Figure 1. Proportions of SVO scores in the overall sample. The solid line represents a Gaussian kernel density estimation. The value with the highest proportion (SVO score $=7.82)$ corresponds to a perfectly selfish individual. 


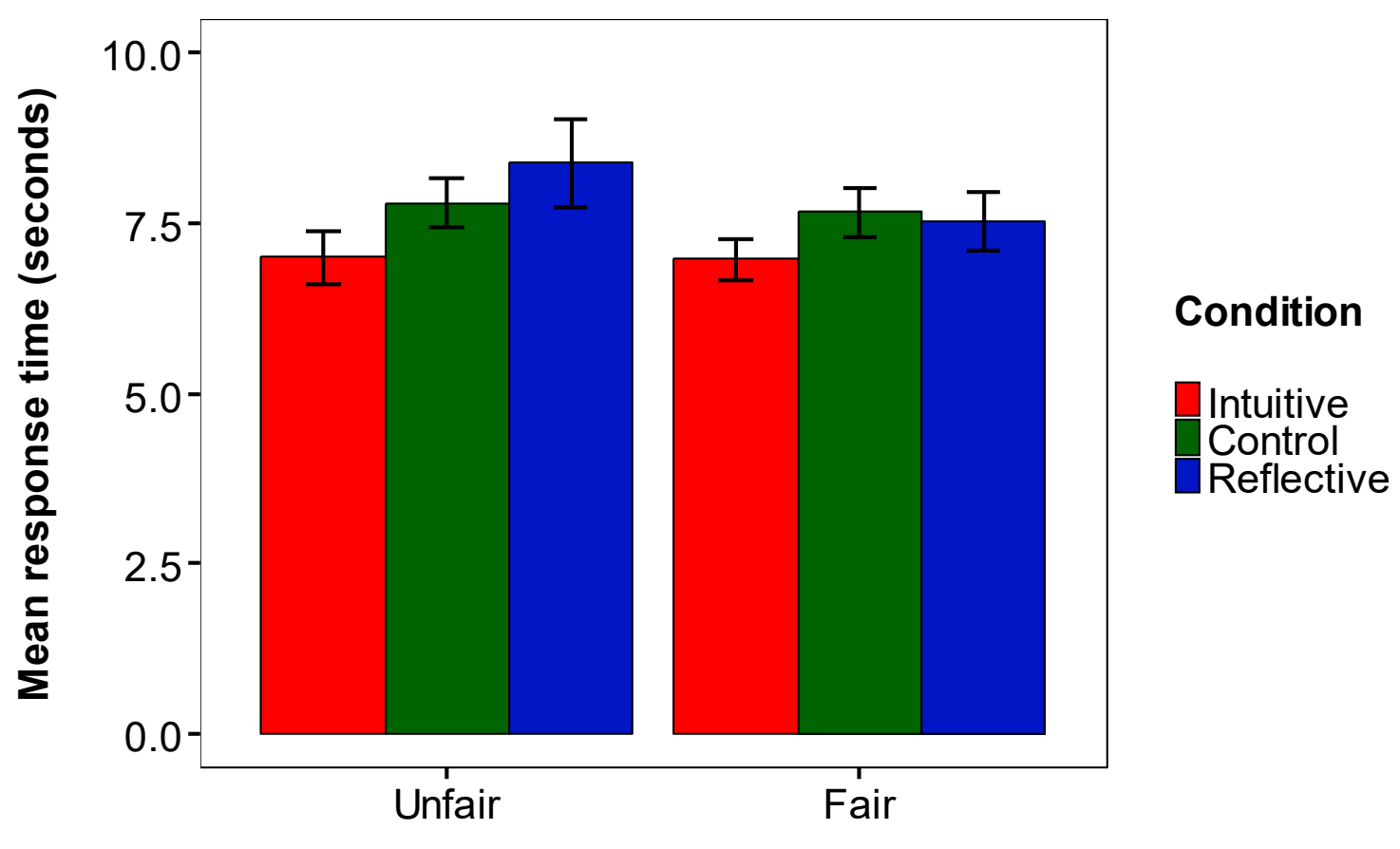

Fairness

Figure 2. Average response times as a function of condition and fairness. Error bars represent standard errors of the mean. 


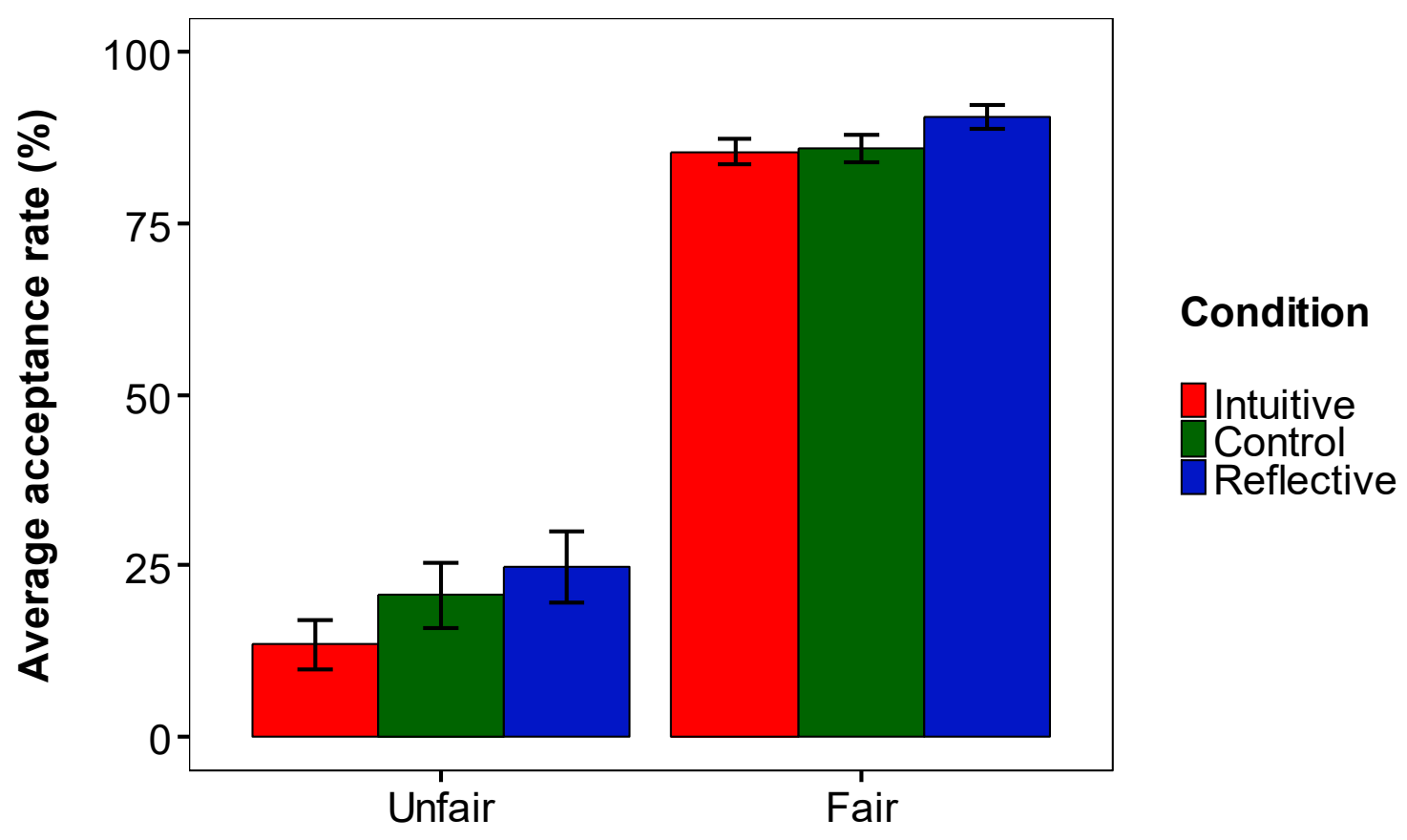

Fairness

Figure 3. Average acceptance rates as a function of condition and fairness. Error bars represent standard errors of the mean. 


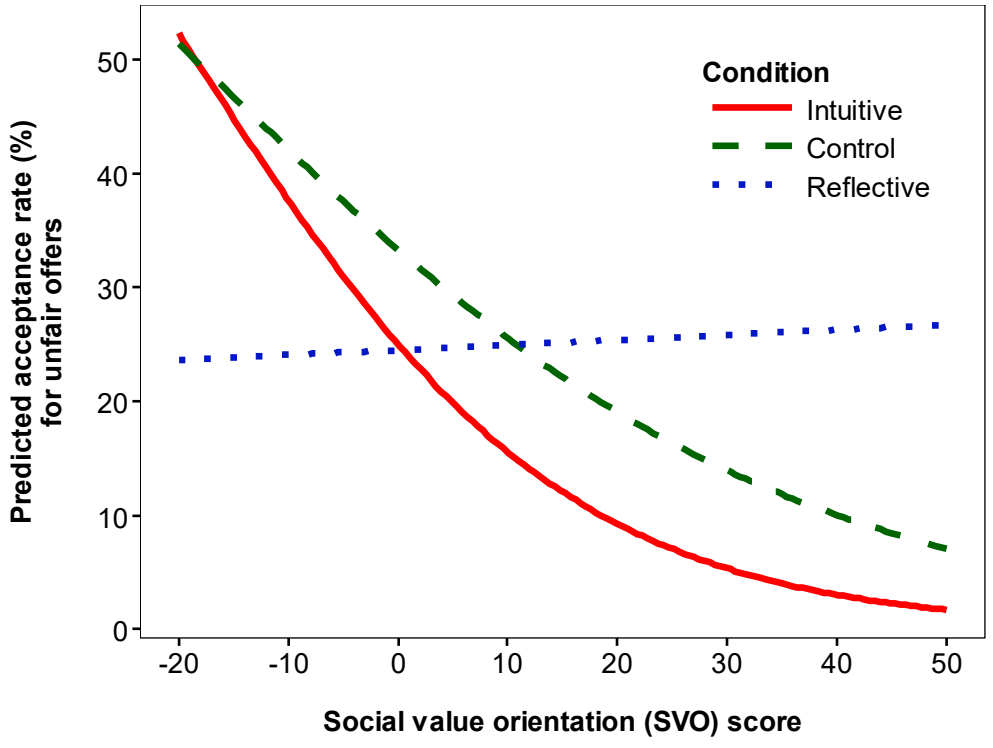

Figure 4. The estimated acceptance rate for unfair offers as a function of SVO score and mode of processing condition. 


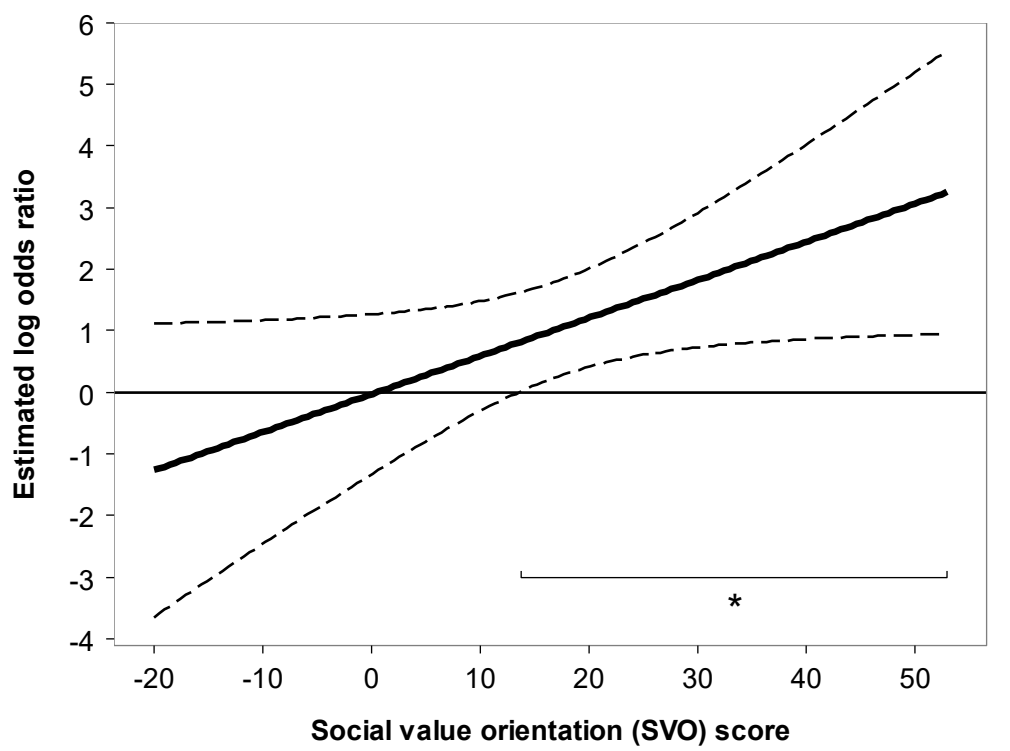

Figure 5. The estimated log odds ratio (solid line) of accepting an unfair offer when belonging to the reflective rather than the intuitive condition as a function of SVO. The dashed lines correspond to the $95 \% \mathrm{CI}$. 


\section{Appendix}

Table A1

Descriptive statistics of the variables assessed in the experiment and their intercorrelations

\begin{tabular}{|c|c|c|c|c|c|c|c|c|c|c|c|c|c|c|c|c|}
\hline & & $M$ & $S D$ & 1 & 2 & 3 & 4 & 5 & 6 & 7 & 8 & 9 & 10 & 11 & 12 & 13 \\
\hline \multirow[t]{2}{*}{1.} & SVO Score & 18.86 & 13.61 & - & .405 & .875 & .254 & .798 & .385 & .954 & .752 & .937 & .680 & .066 & .024 & .515 \\
\hline & REI & & & & & & & & & & & & & & & \\
\hline 2. & FI & 4.93 & 0.85 & .068 & - & .008 & .017 & .634 & .596 & .462 & .149 & .079 & .275 & .270 & .895 & .068 \\
\hline \multirow[t]{2}{*}{3.} & $\mathrm{NC}$ & 4.24 & 0.73 & -.013 & -.212 & - & .307 & .002 & .609 & .738 & .492 & .084 & .983 & .247 & .125 & .584 \\
\hline & PANAS & & & & & & & & & & & & & & & \\
\hline 4. & NA & 1.80 & 0.71 & -.092 & -.192 & .083 & - & .023 & .300 & .169 & .149 & .055 & .302 & .904 & .969 & .832 \\
\hline 5. & PA & 2.42 & 0.74 & -.021 & .039 & .242 & .183 & - & .303 & .282 & .844 & .836 & .899 & .798 & .948 & .806 \\
\hline 6. & Understanding & 4.25 & 1.36 & .092 & .056 & -.054 & -.109 & -.108 & - & .015 & .173 & .158 & .229 & .028 & .084 & .095 \\
\hline 7. & Commitment & 4.20 & 1.47 & -.006 & .078 & .035 & -.145 & .113 & .254 & - & .687 & .568 & .851 & .345 & .261 & .827 \\
\hline 8. & Response Time & 7.49 & 2.70 & .026 & -.117 & -.056 & .117 & -.016 & .143 & -.043 & - & $<.001$ & $<.001$ & .277 & .168 & .691 \\
\hline 9. & unfair & 7.71 & 3.42 & .006 & -.142 & -.140 & .155 & -.017 & .149 & -.060 & $(.875)$ & - & $<.001$ & .570 & .561 & 528 \\
\hline 10. & fair & 7.38 & 2.67 & .034 & -.089 & .002 & .084 & -.010 & .127 & -.020 & $(.960)$ & .706 & - & .061 & .021 & .339 \\
\hline 11. & Acceptance Rate & 66.23 & 16.81 & -.149 & -.089 & -.094 & -.010 & -.021 & .229 & .100 & -.088 & .046 & -.151 & - & $<.001$ & $<.001$ \\
\hline 12. & unfair & 19.60 & 32.57 & -.182 & -.011 & -.124 & .003 & -.005 & .181 & .118 & -.112 & .047 & -.187 & $(.857)$ & - & $<.001$ \\
\hline 13. & fair & 87.29 & 13.75 & -.053 & -.147 & -.044 & .017 & -.020 & .175 & .023 & -.032 & .051 & -.078 & (.832) & .457 & - \\
\hline
\end{tabular}

Note. Pearson correlation coefficients are presented below the diagonal, and unadjusted $p$-values are presented above the diagonal. Coefficients in parentheses reflect part-whole relationships. Coefficients which are significant after Holm-adjusting the $p$-values for 78 comparisons are displayed in bold. $\mathrm{SVO}=$ social value orientation; REI = rational-experiential inventory; FI = faith-in-intuition subscale; $\mathrm{NC}=$ need-for-cognition subscale; $\mathrm{PANAS}=$ positive affect negative affect schedule; $\mathrm{NA}=$ negative affect subscale; $\mathrm{PA}=$ positive affect subscale. 
Running head: PROCESSING UNFAIR ULTIMATUM OFFERS34

\section{Intuitive versus Reflective Information Processing Strategy}

\section{Preparation for the decision ${ }^{2}$}

Think about your wishes for the upcoming decisions.

What is your most important wish for the upcoming decisions? What exactly is your wish about?

Please write down this wish now:

- . - . - new page - . - . - . - -

What is the one best outcome of realizing your wish? Please answer in one or two keywords. Now, imagine your one best outcome.

Imagine the events and experiences that you associate with this outcome. Take as much time as you need. Allow these events and experiences to play out and write them down. If you need more space, please continue writing overleaf.

- - - - - - - - new page - - - - - - -

Sometimes things do not work out as we wish. Often, [I: pondering at length, R: acting in a hasty way] stands in the way of realizing a wish. [I: One agonizes over all aspects and hesitates, without reaching a satisfactory solution., R: One rushes through a couple of aspects and acts hastily, not reaching a satisfactory solution.]

[I: Pondering at length, R: Acting in a hasty way] may hinder one from realizing a wish.

Researchers assume that people who [I: ponder at length, R: act in a hasty way] may actually make worse decisions. The main obstacle for the upcoming decisions is thus [I: pondering at length, R: acting in a hasty way].

Now imagine that you [I: ponder at length about, R: act in a hasty way when making] the upcoming decisions. Imagine the events and experiences that you associate with [I: pondering at length about, R: acting in a hasty way when making] the upcoming decisions. Take as much time as you need. Allow these events and experiences to play out and write them down. If you need more space, please continue writing overleaf.

- - - - - - - - - new page - - - - - . - -

To realize your wish, you should thus [I: listen to your guts, R: use your brain]. Research has demonstrated that making if-then plans helps you with this. Therefore, make the following if-then plan:

When I start [I: pondering at length, R: acting in a hasty way], then I will tell myself: [I: Listen to your guts, R: Use your brain]!

Picture this plan in your mind's eye and memorize it. Say the if-then plan three times to yourself. When you have learned the plan by heart, proceed to the next page.

- - - - - - - new page - - - - - - -

Please write down your plan:

When , then I will tell myself:

\footnotetext{
${ }^{2}$ Instructions translated from German. The intuitive (I) versus reflective (R) wordings are given in brackets.
} 